${ }^{1}$ Дніпровський медичний інститут традиційної і нетрадиційної медицини ${ }^{2}$ ДЗ «Дніпропетровська медична академія МОЗ України»

\title{
ОСОБЛИВОСТІ ПІДГОТОВКИ АНГЛОМОВНИХ СТУДЕНТІВ МОЛОДШИХ І СТАРШИХ КУРСІВ НА КАФЕДРАХ ГІГІЄНІЧНОГО ПРОФІЛЮ У ВИЩИХ МЕДИЧНИХ НАВЧАЛЬНИХ ЗАКЛАДАХ
}

\author{
S. V. Abramov ${ }^{1}$, V. M. Baibakov ${ }^{1}$, L. V. Hryhorenko ${ }^{2}$ \\ ${ }^{1}$ Dnipro Medical Institute of Traditional and Non-Traditional Medicine \\ ${ }^{2}$ Dnipropetrovsk Medical Academy

\section{PECULIARITIES OF TRAINING ENGLISH-SPEAKING STUDENTS PROFILE DEPARTMENTS IN MEDICAL SCHOOLS} \\ OF THE JUNIOR AND SENIOR YEARS OF STUDY IN THE HYGIENIC
}

\begin{abstract}
Анотація. У статті показано особливості підготовки англомовних студентів молодших і старших курсів на кафедрах гігієнічного профілю у вищих медичних навчальних закладах. Встановлено, що для англомовних студентів молодших курсів більш актуальним є проведення семінарів з обговореннями доповідей учасників, а для студентів старших курсів - розв'язання ситуаційних завдань із розбором нормативних документів за темою практичного заняття, оцінка факторів навколишнього середовища за допомогою приладів, ведення протокольних зошитів з тем практичних занять і СРС, проміжний і підсумковий контроль за тестами з бази «Крок 2», що обумовлено особливостями навчальної програми з гігієни для іноземних студентів 3 і 6 курсів за спеціальністю «Лікувальна справа». Анкетування, проведене серед англомовних студентів молодших курсів (40 респондентів) за розробленою нами власною анкетою, показало, що іноземні студенти на підготовку до практичного заняття 3 теоретичних дисциплін витрачають: менше 1 год - 6 респондентів (16,6 \%); 1-2 год - 16 (44,4 \%); 2-3 год - 9 (25 \%); більше ніж 3 год 5 (13,8 \%). При підготовці до заняття з клінічних дисциплін англомовні студенти витрачають: менше 1 год - 3 (8,3 \%); 1-2 год 11 (30,5 \%); 2-3 год - 11 (30,5 \%); більше ніж 3 год - 3 (8,3 \%). Зокрема, 25 \% респондентів (69,4 \%) позитивно ставляться до проведення СРС, чверть опитаних - негативно (14 \%). Відповіді на контрольні питання до тем СРС більшість студентів знаходить у матеріалах із мережі «Інтернет» (36 \%) і в навчально-методичному посібнику (33,3 \%), меншість користується підручниками (28 \%), що зумовлено зниженням зацікавленості студентів до навчання.
\end{abstract}

Ключові слова: семінар; гігієнічний профіль; самостійна робота; англомовні студенти; навколишнє середовище.

Abstract. The article describes peculiarities of training English-speaking students of junior and senior years of study in the hygienic profile departments of medical schools. It has been established that for English-language students of junior year of study it is more relevant to hold seminars with discussion of participants' reports, and for senior students - solution of situational tasks with the analysis of normative documents on the topic of practical classes, assessment of environmental factors with a help of devices, maintenance of protocols on the topics of practical classes and IWS, interim and final control on tests from "KROK-2", due to the peculiarities of curriculum on hygiene for foreign students, which study on the $3^{\text {rd }}$ and $6^{\text {th }}$ courses on the specialty "General medicine". The questionnaire, conducted among students of junior year of study (40 respondents), according to our own questionnaire, showed that foreign students spend less than 1 hour on training of theoretical subjects: 6 respondents (16.6\%); $1-2$ hours - 16 (44.4\%); 2-3 hours -9 (25\%); more than 3 hours $-5(13.8 \%)$. Englishspeaking students spend less than 1 hour $-3(8.3 \%)$ when training for classes in the clinical disciplines; $1-2$ hours -11 (30.5\%); $2-3$ hours - 11 (30.5\%); more than 3 hours - 3 (8.3\%). In particular, $25 \%$ of respondents (69.4\%) are positively related to the IWS, a quarter of respondents - negatively (14\%). The majority of students find answers to the control questions from the topics in the Internet (36\%) and in the textbook (33.3\%), and the minority uses textbooks (28\%), which is caused by a decreasing an interest of students in studying.

Key words: seminar; hygienic profile; independent work of student (IWS); English-speaking students; environment. 
Вступ. У статті наведено досвід роботи з організації підготовки англомовних студентів на кафедрі гігієни та екології. Ефективність підготовки іноземних студентів визначається якістю навчання на кафедрі з використанням інноваційних технологій. Набуття навичок самостійної роботи з літературою, індивідуалізація навчання, розв'язання ситуаційних завдань, виступ на студентських конференціях забезпечують високу професійну підготовку англомовних студентів на кафедрах гігієнічного профілю.

Новизна дослідження полягає в обгрунтуванні технології підготовки англомовних студентів молодших і старших курсів на кафедрах гігієнічного профілю в процесі вивчення гігієни за цикловою і семестровою формами навчання.

У роботах [1, 2] запропонована технологія індивідуалізації навчання, яка виражається в тому, що кожен викладач у малих групах (до 10 чоловік) навчає іноземних студентів основ клінічного мислення на клінічних кафедрах. У дослідженнях $[5,6]$ показано ефективну роль студентського наукового товариства в професійно-орієнтованому навчанні студентів-медиків на клінічних кафедрах.

Мета дослідження - проаналізувати сучасні технології підготовки англомовних студентів молодших і старших курсів на кафедрах гігієнічного профілю.

Методи дослідження: анкетування, порівняльний аналіз, медичний (науковий) дискурс, описовий, бібліографічний.

Результати дослідження. Для поліпшення якості засвоєння навчального матеріалу за I семестр 3 дисципліни «Гігієна» для англомовних студентів 3 курсу за спеціальністю «Лікувальна справа» пропонується проводити наприкінці семестру доповіді з презентацією за однією з тем самостійної роботи. Так, наприклад студентами були обрані і підготовлені доповіді за такими темами: «Food poisonings and their prophylaxis», «Hygiene: the importance and impact of hand washing», «Hygienic problems of healthy lifestyle and personal hygiene», «Radioactive pollution of environment and its influence on population health», «Introduction of pollution. Air, land, water and radioactive pollution», «Synthetic food as a new hygienic problem», «Hospital hygiene and the surgeon, anesthesiologist, dresser - nurse occupational hazards and hygiene of labor», «Environmental health hazards», "Carcinogenic factors of occupational condition», «Hygienic value of basic nutrients of food. Properties of food products. Methods of determination and estimation of food status of a human».
Серед англомовних студентів 3 та 6 курсів навчання проводили анкетне опитування щодо організації самостійної роботи (СРС) на кафедрі гігієни та екології. Анкета включала 16 питань. Найбільш актуальними і такими, що повністю відображають сприйняття студентами самостійної роботи, були такі питання: «Скільки часу Ви витрачаєте на підготовку до кожного аудиторного (позааудиторного) заняття - 3 теоретичних і $з$ клінічних дисциплін?», «Які види самостійної роботи Ви виконуєте?», «Ваші побажання щодо вдосконалення організації СРС на кафедрі гігієни та екології» та ін. Найбільш популярними формами підготовки СРС 90 \% опитаних англомовних студентів бачать виступи 3 доповідями та презентаціями за запропонованими викладачем темами СРС із дискусією в кінці семінарського заняття - переважно студенти молодших курсів навчання. Тоді як англомовні студенти старших курсів хотіли б використовувати при підготовці СРС інноваційні методи, такі, як перегляд відеофільмів з теми заняття, прослуховування лекцій у формі вебінарів та інші форми підготовки 3 використанням сучасних комп'ютерних технологій.

На 3 курсі практичні заняття з гігієни проводяться по семестрах. Наприкінці кожного семестру викладач проводить семінар-конференцію з обговоренням доповідей найкращих студентів. Особливістю навчання англомовних студентів молодших курсів $є$ доступне викладання предмета, з комбінацією усного та письмового опитування. На кафедрах гігієнічного профілю особлива увага приділяється розбору практичних навичок роботи з приладом. Так, наприклад, під час практичних занять викладач розбирає разом із студентами принципи роботи люксметра, психрометра, анемометра, батометра, апарата Кротова, біодозиметра Горбачова, шумоміра, актинометра. 3 метою апробації отриманих результатів на кафедрі гігієни та екології впроваджені протоколи лабораторних досліджень факторів навколишнього середовища для англомовних студентів молодших і старших курсів.

Наприкінці I семестру англомовні викладачі кафедри проводили засідання студентського наукового товариства (СНТ), у якому брали участь англомовні студенти молодших курсів. Доповіді учасників конференції були представлені англійською мовою за такими темами: «Chemical pollution: definition and prevention», «Comparative characteristic of methods of water purification», «Hygienic requirements to nutrition for a pregnant woman», «Hygienic significance of using food from 
sea for health». Конференція була присвячена питанням безпеки і екології «Еcology and safety: first experience».

За підсумками конференції було опубліковано тези в збірнику доповідей підсумкової конференції СНТ «Учитель і учень - 2018». Під науковим керівництвом авторів цих рядків були опубліковані тези найкращих доповідей серед англомовних студентів 3 курсу I міжнародного факультету за спеціальністю «Лікувальна справа»: «Non-community drinking water system characteristics in the rural settlements», «Contamination of Dnipropetrovsk region centralized water supply sources with nitrates», «Municipal wastewater application at the formation of secondary ecosystems», «Suitability of wastewater sludge for landscape reclamation in Krivoy Rog iron mining ore deposit companies», "Interpreting the water quality (by the results of sociological survey)», «Availability of drinking water usage in the rural settlements and Dnipro city population».

На відміну від англомовних студентів молодших курсів, для студентів старших курсів передбачено циклову систему навчання. Загальна тривалість циклу становить 8 днів, а практичні заняття та лекції проводяться одним блоком. Наприкінці циклу на кафедрах гігієнічного профілю англомовні студенти 6 курсів складають підсумковий модуль, який передбачає написання тестів з бази «Крок 2» $з$ усіх розділів гігієни та перевірку викладачем заповнених у протокольних зошитах 10 тем СРС. Для поліпшення якості підготовки англомовних студентів 6-го курсу II міжнародного факультету за спеціальністю «Лікувальна справа» до складання ліцензійного іспиту «Крок 2» щодня проводиться тренінг у режимі контролю в комп’ютерному клаci, обладнаному сучасними комп'ютерами, з усіх розділів гігієни, які складаються із 7 модулів: «Комунальна гігієна», «Гігієна харчування», «Гігієна праці», «Гігієна дітей та підлітків», «Радіаційна гігієна», «Загальні питання гігієни та екології», «Гігієна надзвичайних ситуацій».

Особливістю навчання іноземних студентів старших курсів є більший обсяг тем СРС, розв'язання ситуаційних завдань, вміння працювати з нормативними документами гігієнічного профілю, здача практичних навичок за приладами, проміжний і підсумковий тренінг по тестах з бази «Крок 2».

Крім того, іноземні студенти (англомовна форма навчання) складають державний іспит 3 гігієни, який включає такі основні елементи, як: розв’язання ситуаційної задачі, вміння працювати
3 нормативним документом, здача практичної навички за приладами, вміння надавати гігієнічну оцінку ситуації, визначати фактори ризику для здоров'я населення, складати план гігієнічних рекомендацій, характеризувати методики визначення факторів навколишнього середовища.

3 огляду на відсутність базових національних підручників з гігієни для студентів старших курсів, адаптованих для викладання англійською мовою, англомовні викладачі кафедри гігієни та екології створили навчально-методичну продукцію для іноземних студентів: protocols of practical study for English - speaking students of 6 courses on the «Hygiene and ecology of a human», speciality «Medical department»; protocols of practical study for English - speaking students of 3 courses on the «General hygiene», speciality «Medical department»; guideline for practical training on «Hygiene and Ecology» for 6 courses students of International faculty, specialty «General Medicine»; guideline for practical training on «General hygiene» for 3 courses students of International faculty, specialty «General Medicine» та інші.

3 огляду на специфіку дисциплін гігієнічного профілю, слід зазначити, що при комплексній оцінці факторів навколишнього середовища студенту необхідно використовувати гігієнічні регламенти. Більшість нормативних документів було перекладено англійською мовою й адаптовано до умов українських реалій: State Sanitary Rules-201-97 «Protection atmospheric air from pollution», Scale for assessment of sanitary state of soil, Hygienic demands to hospital environment, «State sanitary rules and norms on the device, maintenance of general educational institutions and the organization of teaching and educational process» № 5.5.2.008-01, «State sanitary rules and norms safety of toys and games for children's health» № 5.5.6.012-98 order by Ministry of Health of Ukraine, «Hygienic requirements to the printed matter for children» № 13 order 18.01.2007 year by Ministry of Health of Ukraine, «Physiologic amounts for major dietary ingredients and energy» order 18.11.1999 year by Ministry of Health of Ukraine, «Admissible level of maintenance radioisotopes $137 \mathrm{Cs}$ and $90 \mathrm{Sr}$ in the foodstuff and potable water. Values of admissible levels of radioisotopes $137 \mathrm{Cs}$ and $90 \mathrm{Sr}$ in the foodstuff and potable water $(\mathrm{Bk} / \mathrm{kg}, \mathrm{Bk} / \mathrm{l}) »$, State sanitary rules and norms «Hygienic requirements to drinking water, intended for human consumption» № 2.2.4-171-10 тощо. Однак, крім національних стандартів, при підготовці лекційного курсу викладач знайомить 
англомовних студентів з вимогами міжнародних стандартів, класифікацією хвороб водного походження, хворобами тропічних країн.

Окрім того, для полегшення засвоєння навчального матеріалу, в практичні заняття та лекційний курс впроваджено монографії англійською мовою для іноземних студентів [3, 4]. При проведенні заняття 3 модуля «Гігієна харчування», наприклад, іноземні студенти користуються таблицею (табл. 1) для розрахунку і оцінки індексу маси тіла, представленою в монографії [3]. Монографія «Аліментарне ожиріння як гігієнічна проблема» написана двома мовами і призначена для англомовних і російськомовних іноземних студентів медичних факультетів вищих медичних навчальних закладів III-IV рівнів акредитації.

Таблиця 1. Класифікація нестачі і надлишку ваги в дорослих згідно з індексом маси тіла (IMT) (BOO3, 2000)

\begin{tabular}{|c|c|c|}
\hline Класифікація & 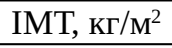 & Опис популяції \\
\hline недостатня вага & $<18,5$ & худий \\
\hline діапазон норми & $18,5-24,9$ & нормальний, здоровий, прийнятна вага \\
\hline надлишок ваги & $\geq 25$ & зайва вага \\
\hline преожиріння & $25-29,9$ & зайва вага \\
\hline повний, I ступінь & $30,0-34,9$ & ожиріння \\
\hline повний, II ступінь & $35,0-39,0$ & ожиріння \\
\hline повний, III ступінь & $\geq 40$ & патологічне ожиріння \\
\hline
\end{tabular}

Висновки та перспективи подальших досліджень. Особливості підготовки англомовних студентів на кафедрах гігієнічного профілю відрізняються за навчальною програмою для іноземців молодших і старших курсів. Для англомовних студентів молодших курсів найбільш пріоритетними є: проведення семінарів-конференцій $з$ обговоренням доповідей учасників, участь у засіданнях СНT, публікація тез, розбір практичних навичок з наочною демонстрацією методики вимірювання факторів середовища, письмовий або усний контроль теоретичної підготовки студента. Для студентів старших курсів пріоритетними є: підготовка до написання тестів «Крок 2», розв’язання ситуаційних завдань, вміння оцінювати фактори навколишнього середовища і знати методику вимірювання цих факторів за допомогою приладів, заповнення протокольних зошитів за темами практичних занять і СРС.

У лекційний курс необхідно включати гігієнічні заходи з профілактики інфекційних та неінфекційних захворювань, особливо в країнах із тропічним кліматом, насамперед гігієнічне нормування факторів навколишнього середовища за вимогами національних та міжнародних стандартів.

3 огляду на незначну кількість національних підручників для англомовних іноземців з дисциплін гігієнічного профілю, рекомендується використовувати і періодично оновлювати нормативну базу гігієнічних стандартів, перекладених англійською мовою; використовувати монографії та навчальні посібники англійською мовою, адаптовані до тем практичних занять та лекційного курсу для іно- земних студентів англомовної та російськомовної форм навчання.

Анкетування, проведене серед англомовних студентів молодших курсів (40 респондентів) за розробленою нами власною анкетою, показало, що іноземні студенти на підготовку до практичного заняття з теоретичних дисциплін витрачають: менше 1 год - 6 респондентів (16,6 \%); 1-2 год 16 (44,4 \%); 2-3 год - 9 (25 \%); більше ніж 3 год 5 (13,8 \%). При підготовці до заняття з клінічних дисциплін англомовні студенти витрачають: менше 1 год - 3 (8,3 \%); 1-2 год - 11 (30,5 \%); 2-3 год 11 (30,5 \%); більше ніж 3 год - 3 (8,3 \%). Зокрема, 25 \% респондентів (69,4 \%) позитивно ставляться до проведення СРС, чверть опитаних - негативно (14\%). Відповіді на контрольні питання до тем СРС більшість студентів знаходить у матеріалах 3 мережі «Інтернет» (36 \%) і у навчально-методичному посібнику (33,3 \%), меншість користується підручниками та іншими джерелами (28 \%), що зумовлено зниженням зацікавленості студентів до навчання, незалежно від типу дисципліни (клінічна або практична).

Перспективи подальших досліджень: встановлення причинно-наслідкових зв’язків щодо зниження інтересу іноземних студентів при підготовці до вивчення дисципліни 3 клінічної або теоретичної кафедри; збільшення вмотивованості серед англомовних викладачів у зацікавленості студентів предметом шляхом проведення майстер-класів, тренінгів, стажування в інших вищих навчальних закладах, у тому числі - за кордоном.

Конфлікт інтересів: відсутній. 


\section{Список літератури}

1. Ашеров А. Т. Професійні якості спеціаліста - як компонент культури освіти / А. Т. Ашеров , В. І. Шеховцева, Ю. М. Полякова // Бюлетень НТУУ «КПИ»: філософія, психологія, освіта. - 2010. - № 2 (29). - С. 127-132.

2. Пузирьов $€$. В. Система освіти студентів технічних університетів / Є. В. Пузирьов // Молодий вчений. 2015. - № 2 (17). - С. 299-302.

3. Alimentary obesity as hygienic problem / L. I. Byrjak, E. N. Belitskaya, S. A. Shchudro, L. V. Gryhorenko. Dnepropetrovsk : Porogy, 2012. - 273 p.

4. Hryhorenko L. V. Effects of poor potable water quality on the health of peasants - inhabitants of Dnepropetrovsk

\section{References}

1. Asherov, A.T., Shekhovtseva, V.I., \& Poliakova, Yu.M. (2010). Profesiini yakosti spetsialista - yak komponent kultury osvity [Professional qualities of a specialist - as a component of the culture of education]. Biuleten NTUU "KPI": filosofiia, psykholohiia, osvita - Bulletin of the NTUU “Kyiv Polytechnic Institute”: Phylosophy, Psychology, Education, 2 (29), 127-132 [in Ukrainian].

2. Puzyriov, Ye.V. (2015). Systema osvity studentiv tekhnichnykh universytetiv [Education system of students of technical universities]. Molodyi vchenyi - Young Scientist, 2 (17), 299-302 [in Ukrainian].

3. Byrjak, L.I., Belitskaya, E.N., Shchudro, S.A., \& Gryhorenko, L.V. (2012). Alimentary obesity as hygienic problem. Dnepropetrovsk: "Porogy".

4. Hryhorenko, L.V., \& Shevchenko, A.A. (2016). Effects of poor potable water quality on the health of peasants - rural settlements (by the sociological survey and results of own research) / L. V. Hryhorenko, A. A. Shevchenko. - Saarbrücken : LAP LAMBERT Academic Publishing, 2016. 101 p. - Access mode : http://dnb.d-nb.de.

5. Role of lecture in the modern education system / S. B. Kramar, D. I. Nasarova, M. Yu. Zharikov [et al.] // European Applied Sciences. - 2015. - No. 4. - P. 22-24.

6. Student scientific society: Key role in the professional training of medical specialists in the higher medical schools / S. B. Kramar, D. I. Nazarova, Yu. V. Silkina [et al.] // European Applied Sciences. - 2016. - No. 11. P. 17-20.

inhabitants of Dnepropetrovsk rural settlements (by the sociological survey and results of own research. Saarbrücken "LAP LAMBERT Academic Publishing”. Retrieved from: http://dnb.d-nb.de.

5. Kramar, S.B., Nasarova, D.I., Zharikov, M.Yu., Lukianenko, D.M., Hryhorenko, L.V., Shevchenko, I.N., Baibakov, V.M., \& Stepanskyi, D.O. (2015). Role of lecture in the modern education system. European Applied Sciences, 4, 22-24.

6. Kramar, S.B., Nazarova, D.I., Silkina, Yu.V., Baibakov, V.M., Lukianenko, D.M., \& Hryhorenko, L.V. (2016). Student scientific society: Key role in the professional training of medical specialists in the higher medical schools. European Applied Sciences, 11, 17-20. 